\title{
GESTÃO DE RISCO FINANCEIRO
}

Os investimentos em ativos financeiros são incertos porque não se conhecem com exatidão os retornos e fluxos de caixa futuros. Risco corresponde à medição dessa incerteza, e pode ser segmentado em diversas categorias, como risco de mercado, risco de crédito, risco operacional, risco de liquidez e risco legal. A importância da Gestão de Risco Financeiro é crescente em instituições financeiras por conta de aspectos regulatórios, como o novo Acordo de Basiléia, do aumento do volume e complexidade das transações financeiras, do surgimento de novos instrumentos derivativos e de novas formas de mitigar riscos. Andrea Minardi, professora do IBMEC São Paulo, recomenda as seguintes indicações na área:

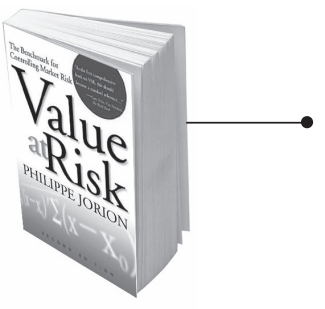

VALUE AT RISK: The New Benchmark for Managing Financial Risk. Philippe Jorion. 3th ed. New York: McGrawHill, 2006. 600 p.

A obra se tornou referência sobre o tema desde sua primeira edição, quando discutiu os sistemas e as variáveis do value-at-risk (VAR). O VAR permite rastrear e estimar os riscos de mercado, possibilitando às instituições financeiras tomar medidas proativas para controlar tais riscos. A terceira edição inclui capítulos sobre risco de crédito, risco de liquidez, risco operacional e visão integrada do risco. Discute novas aplicações em gestão de risco e alterações de definições dos padrões das indústrias.

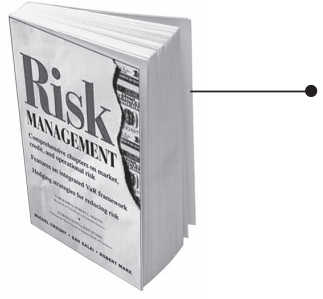

RISK MANAGEMENT. Michel Crouhy, Dan Galai e Robert Mark. New York: McGraw-Hill, 2000. 752 p.

A obra é ambiciosa no sentido de procurar ser um guia único para gestores financeiros e de instituições bancárias para implementar e utilizar efetivamente programas de gestão de risco, buscando englobar as categorias de risco de mercado, risco de crédito e risco operacional. Descreve bem os aspectos de Basiléia I e a necessidade para um novo acordo, e os capítulos que explicam os quatro principais modelos de gestão de risco de crédito - CreditMetrics, KMV, CreditRisk+e CreditPortfolioView - são excelentes.

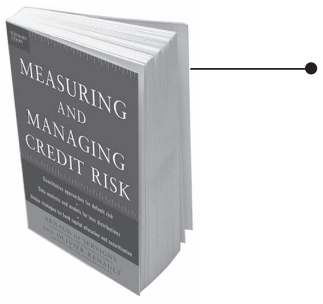

MEASURING AND MANAGING CREDIT RISK. Arnaud de Servigny e Olivier Renault. New York: McGraw-Hill, 2004. $466 \mathrm{p}$.

Escrito por dois diretores da Standard \& Poor's, a obra fornece uma visão bastante atual e completa das várias dimensões do risco de crédito: metodologias qualitativas e quantitativas para estimar risco de inadimplência, perdas em caso de inadimplência, dependências de inadimplência, alocação estratégica de capital, curvas de spread, produtos estruturados e derivativos de crédito e regulamentação. Os apêndices são dedicados aos leitores que pretendem se aprofundar quantitativamente em algumas ferramentas.
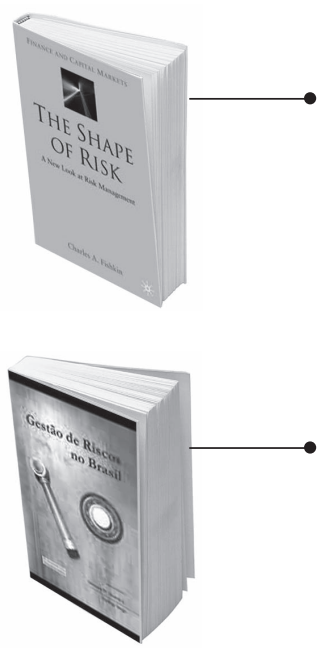

THE SHAPE OF RISK: A New Look at Risk Management. Charles A. Fishkin. New York: Palgrave Macmillan, 2006. $400 \mathrm{p}$.

Escrito pelo diretor da United States Security and Exchange Comission (SEC), responsável pela avaliação de risco, a obra discute o que ocorre dentro das organizações que praticam gestão de risco. Adicionalmente, descreve como o gestor de risco pensa e age, e discute diversos problemas e situações práticas. A seleção de tópicos reflete os desafios práticos de gestores de risco nas mais diversas dimensões.

GESTÃO DE RISCOS NO BRASIL. Antônio Marcos Duarte Jr. e Gyorgy Varga (Orgs.). Rio de Janeiro: Financial Consultoria, 2003. 833 p.

A obra é uma coletânea de artigos de diversos autores, tanto acadêmicos como profissionais do mercado, que explicam as práticas e ferramentas de gestão de risco utilizadas no Brasil. Os artigos estão organizados em função dos diversos tipos de riscos: corporativos, de mercado e de liquidez, de crédito, operacionais, em fundos de investimento, em fundos de pensão e em empresas. 